Ataturk Education and Research Hospital, Rheumatology Clinic, Izmir, Turkey; ${ }^{4}$ Izmir Katip Celebi Unviersity, Faculty of Medicine, Department of Internal Medicine, Division of Rheumatology, Izmir, Turkey

Background: Familial Mediterranean fever (FMF) is an auto-inflammatory disease commonly affects people from Mediterranean basin. It is characterized by acute self-limiting inflammatory attacks of serous membranes. The disease is commonly associated with musculoskeletal symptoms of lower extremities such as arthritis, exercise induced leg pain, as well as protracted febrile myalgia. The term of anaerobic exercise capacity describes the ability of performing quick and explosive tasks such as stair climbing and brisk walking. It is well known that anaerobic exercise capacity is closely related to functional status.

Objectives: To assess the relationship between anaerobic exercise capacity and lower extremity functionality in patients with FMF.

Methods: Twenty-eight FMF patients (57\% female) were included in the study. Median age was 33.5 (IQR 25/75: 23.3/44.3) years, median body mass index was 24.3 (IQR 25/75: $21.0 / 27.8) \mathrm{kg} / \mathrm{m}^{2}$ median time since symptom onset was 20.0 (IQR 25/75: 11.5/24.5) years, median time since diagnosis was 10.0 (IQR 25/75: 3.75/17.5) years, and median colchicine dosage was 1.5 (IQR 25/75: 1.0/1.5) $\mathrm{mg} /$ day. Anaerobic exercise capacity was measured with Wingate Anaerobic Test by using a cycle ergometer. Peak power (watt $/ \mathrm{kg}$ ) and average power (watt $/ \mathrm{kg}$ ) were calculated. Stair climbing, standing from a chair, and walking were assessed by using 9-step stair climb test, 10-repetition chair stand test, and 6 -minute walking distance, respectively. Spearman's rank-order correlation test was used to analyse the relationships between anaerobic exercise capacity and lower extremity functional tests.

Results: The results of the anaerobic exercise capacity and lower extremity functional test scores of patients with FMF were summarized in table 1. Moderate relationships were found between both peak and average anaerobic exercise capacities and lower extremity functional status tests (Table 1, p<0.05). Six-minute walking distance has the strongest association with both peak (rho: .672, $\mathrm{p}<0.001$ ) and average (rho: .689, $\mathrm{p}<0.001$ ) anaerobic exercise capacity.

Table 1. Anaerobic exercise capacity scores and lower extremity functionality as well as the relationships between anaerobic capacity and functional tests in patient with familial Mediterranean fever.

\begin{tabular}{|c|c|c|c|}
\hline \multirow[t]{2}{*}{ Characteristics } & \multirow[t]{2}{*}{$\begin{array}{l}\text { Median (IQR 25/75) } \\
\text { (n:28) }\end{array}$} & \multicolumn{2}{|c|}{$\begin{array}{l}\text { The correlation results, rho, } \\
\text { p values }\end{array}$} \\
\hline & & $\begin{array}{l}\text { Peak Power } \\
\text { (watt/kg) }\end{array}$ & $\begin{array}{l}\text { Average Power } \\
\text { (watt/kg) }\end{array}$ \\
\hline 9-step stair climb test (seconds) & $5.7(5.1 / 6.4)$ & $\begin{array}{l}-.590^{\star} \\
\text { p:0.001 }\end{array}$ & $\begin{array}{l}-.648^{\star} \\
\mathrm{p}: 0.001\end{array}$ \\
\hline 10-repetition chair stand test (seconds) & $16.6(13.7 / 18.7)$ & $\begin{array}{l}-.493^{\star} \\
\text { p:0.008 }\end{array}$ & $\begin{array}{l}-.476^{\star} \\
\text { p:0.010 }\end{array}$ \\
\hline 6-minute walking distance (meters) & $594.1(551.1 / 643.3)$ & $\begin{array}{l}.672^{*} \\
\mathrm{p}<0.001\end{array}$ & $\begin{array}{l}.689^{\star} \\
\mathrm{p}<0.001\end{array}$ \\
\hline $\begin{array}{l}\text { Peak power (watt } / \mathrm{kg}) \\
\text { Average power (watt/kg) }\end{array}$ & $\begin{array}{l}5.8(4.1 / 7.9) \\
4.6(3.1 / 5.9)\end{array}$ & & \\
\hline
\end{tabular}

IQR 25/75: Interquartile range between $25^{\text {th }}$ and $75^{\text {th }}$ percentiles; kg: kilograms, *Spearman's rank-order correlation test, $p<0.05$.

Conclusion: According to our results, anaerobic exercise capacity is related to lower extremity functional status in patients with FMF. Improving anaerobic capacity by using optimal rehabilitation programs including speed and agility exercises may help to improve anaerobic exercise capacity, and consequently lower extremity functionality in those patients.

Disclosure of Interests: None declared

DOI: 10.1136/annrheumdis-2021-eular.2380

\section{AB0863-HPR FUNCTIONAL STATUS ASSESSMENT THROUGH SELF-REPORTED QUESTIONNAIRES IN RHEUMATIC DISEASES}

P. Herrera-Sandate ${ }^{1}$, D. Vega-Morales ${ }^{1}$, A. L. De-Leon-lbarra ${ }^{1}$, P. ValdesTorres $^{2}$, L. A. Chavez-Alvarez ${ }^{1}$, A. Limon-del Toro ${ }^{1}$, I. D. J. Hernandez-Galarza ${ }^{1}$, R. Pineda-Sic ${ }^{1}$, D. Á. Galarza-Delgado ${ }^{1}{ }^{1}$ Hospital Universitario Dr. José Eleuterio González, Rheumatology Service, Monterrey, Mexico; ${ }^{2}$ Hospital Universitario Dr. José Eleuterio González, Sports Medicine and Physical Rehabilitation Department, Monterrey, Mexico

Background: Health and disease status assessment is of paramount importance in rheumatic diseases. Self-report functional status questionnaires provide a cost and time-efficient means of systematic evaluation for physicians. The Health Assessment Questionnaire (HAQ) is one of the most utilized comprehensive measures of outcome, and is divided in 8 sections of activity domains, namely, dressing, arising, eating, walking, hygiene, reach, grip and outside activities. Other disease-specific instruments such as the Western Ontario and McMaster Osteoarthritis Index (WOMAC) share most of the functional domains evaluated by $\mathrm{HAQ}$, whereas Bath Ankylosing Spondylitis Disease Activity Index (BASDAI) and WOMAC share domains mostly regarding pain and stiffness. Here, we present the results of the application of self-administered surveys in a thirdlevel reference center in Mexico.

Objectives: Determine the functional status and most affected activity domains of patients with rheumatic diseases measured by generic (HAQ) and disease-specific (WOMAC and BASDAI) questionnaires in a reference center of northeastern Mexico.

Methods: We carried out a cross-sectional study in Rheumatology consultation in University Hospital "Dr. José Eleuterio González" in Monterrey, Mexico from August 2019 to December 2020. Nursery personnel systematically applied self-reported questionnaires $\mathrm{HAQ}$, WOMAC and BASDAl in patients during their medical follow-up. Patient-reported outcomes were categorized by HAQ activity domains and/or pain and stiffness symptoms in WOMAC and BASDAI. Demographical characteristics were retrieved as well.

Results: Demographic characteristics are shown in Table 1. HAQ showed a higher prevalence of difficulty performing daily activities in the Grip domain. WOMAC question regarding heavy domestic duties had the higher degree of difficulty, as well as pain ascending stairs and stiffness after awakening. Fatigue was the most severe symptom in BASDAl, followed by pain in areas tender to touch and pressure and stiffness after awakening

Conclusion: Disease activity and functional status impact is present on a mild-moderate level in self-reported questionnaires in the Rheumatology consultation of a northeastern center of reference in Mexico. The most affected domain in patients with rheumatic diseases is Grip domain, the most affected daily activities to perform are heavy domestic duties and the most prevalent symptoms are pain ascending stairs and stiffness after awakening as measured by $\mathrm{HAQ}$ WOMAC and BASDAI, respectively.

\section{REFERENCES:}

[1] Ferreira, P. L., Gonçalves, S. P., Ferreira, L. N., Pereira, L. N., Antunes, P., Gouveia, N., Rodrigues, A., Canhão, H., \& Branco, J. (2016). Assessing quality of life of self-reported rheumatic patients. Rheumatology international, 36(9), 1265-1274. https://doi.org/10.1007/s00296-016-3517-0.

Table 1. Clinical and demographic characteristics of self-reported questionnaires HAQ, WOMAC and BASDAI.

\begin{tabular}{ll}
\hline HAQ & $\mathrm{n}=293$ \\
\hline Female, $\mathrm{n}(\%)$ & $53.96(95.6 \%)$ \\
Age in years, mean (SD) & $51.96(14.2)$ \\
Mean score & 0.8 \\
WOMAC & $\mathrm{n}=59$ \\
Female, $\mathrm{n}(\%)$ & $56(94.9 \%)$ \\
Age in years, mean (SD) & $61.64(9.19)$ \\
Mean score & $35.6 \%$ \\
BASDAl & $\mathrm{n}=8$ \\
Male, $\mathrm{n}(\%)$ & $5(62.5 \%)$ \\
Age in years, mean (SD) & $42.12(14.77)$ \\
Mean score & 4.98
\end{tabular}

HAQ, Health Assessment Questionnaire; WOMAC, Western Ontario and McMaster Osteoarthritis Index; BASDAI, Bath Ankylosing Spondylitis Disease Activity Index; SD, standard deviation.

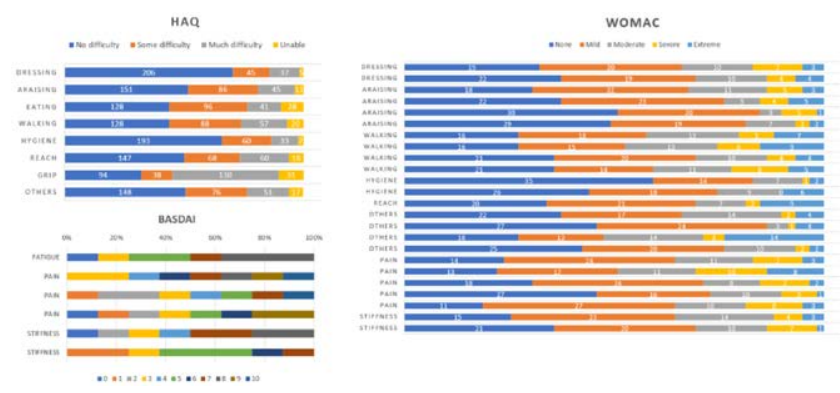

Figure 1. $H A Q$, WOMAC and BASDAI questions arranged by $H A Q$ activity domains and/or symptoms showing the prevalence of difficulty degree per activity.

Disclosure of Interests: None declared DOI: 10.1136/annrheumdis-2021-eular.2781

\section{AB0864-HPR INFLUENCE OF THE TYPE OF PAIN SYNDROME ON THE SEVERITY OF ANXIETY-DEPRESSIVE DISORDERS IN PATIENTS WITH RHEUMATOID ARTHRITIS}

E. Egorova ${ }^{1}$, N. Nikitina2, A. Rebrov ${ }^{1} .{ }^{1}$ Saratov State Medical University name of V.I. Razumovsky Ministry of Health of Russia, Hospital Therapy, 
Saratov, Russian Federation; ${ }^{1}$ Saratov State Medical University name of V.I. Razumovsky Ministry of Health of Russia, Hospital Therapy, Saratov, Russian Federation

Background: Rheumatoid arthritis (RA) is a chronic autoimmune disease that leads to joint damage and deformation. Pain syndrome, along with functional limitations, causes the emergence of anxiety-depressive disorders. The patient's psycho-emotional characteristics affect the patient's quality of life and the effectiveness of the therapy. The aim: to assess the severity of anxiety and depression in women with rheumatoid arthritis, depending on the type of the pain syndrome.

Objectives: The study included 163 women with RA according to the EULAR / ACR 2010 criteria (age 53,9 $\pm 10,15$ years, RA duration - 10 [4; 14] years, DAS28 $-5,03[4,35 ; 5,8])$.

Methods: We used the Hospital Depression and Anxiety Scale (HADS) questionnaire: 0-7 points were assessed as the absence of significant symptoms of anxiety and depression, 8-10 points - subclinically expressed anxiety and depression, more than 11 points - clinically expressed anxiety and depression. The severity of pain was determined by the VAS: no pain $(0-4 \mathrm{~mm})$, mild pain $(5-44 \mathrm{~mm})$, moderate pain $(45-74 \mathrm{~mm})$, severe pain $(75-100 \mathrm{~mm})$. Assessment of the type of pain (identification of the neuropathic component of pain) was carried out using the DN4 questionnaire: a sum of 4 or more points indicated the presence of a neuropathic component of pain (NCP). Statistical processing was performed using the STATISTICA 10,0 program.

Results: The frequency of occurrence of anxiety-depressive disorders in RA patients was determined: clinically pronounced anxiety was detected in 35 $(21,4 \%)$ patients, depression - in $34(20,9 \%)$; subclinically expressed anxiety - in $42(25,8 \%)$, depression - in $44(27 \%)$ patients; absence of reliably pronounced symptoms of anxiety - in $86(52,8 \%)$ patients, depression - in 85 $(52,1 \%)$ patients.

Severe pain according to VAS was noted in 57 (35\%) patients, moderate pain - in 75 (46\%), in 31 (19\%) patients the pain syndrome was mild. In $81(49,7 \%)$ patients a neuropathic component of pain was revealed.

The relationship was established between the presence of NCP and the severity of anxiety $(r=0,27, p<0,05)$, depression $(r=0,31, p<0,05)$. The relationship was revealed between the presence of NCP and the severity of pain according to the VAS $(r=0.32, p<0.05)$.

To explain the relationship between the presence of NCP and anxiety-depressive disorders, the patients were divided into two groups depending on the presence of NCP, comparable in age, the main clinical characteristics of RA, and basic therapy. The level of anxiety in women with NCP $(9,5[7 ; 13])$ was significantly higher than in patients without NCP $(6.1[4 ; 9])(p=0.01)$. The severity of depression in women with NCP was $8,55[6 ; 11]$, in patients without NCP $-5,15[3 ; 6]$ $(p=0.005)$.

Conclusion: Thus, every fifth patient with RA had clinically significance anxiety and depression, subclinical anxiety and depression were found in $26 \%$ of RA patients. Most of the patients $(81 \%)$ had moderate or severe pain, half of the patients had signs of neuropathic pain. The relationship between the severity of anxiety and depression with the intensity of pain and the presence of a neuropathic component was revealed

Disclosure of Interests: None declared

DOI: 10.1136/annrheumdis-2021-eular.2795

\section{AB0865-HPR FREQUENCY OF DEPRESSION IN SYSTEMIC LUPUS ERYTHEMATOSUS}

L. Cano Garcia ${ }^{1}$, S. Manrique Arija ${ }^{1}$, F. Godoy-Navarrete ${ }^{1}$, A. M. CabezasLucena', G. Diaz-Cordobes ${ }^{1}$, N. Mena-Vázquez ${ }^{1} .{ }^{1}$ Hospital Regional Universitario de Málaga, Rheumatology, Málaga, Spain

Objectives: Cross-sectional observational study of a series of SLE patients selected from the Rheumatology consultations.

Methods: age $\geq 18$ years with SLE (ACR 1997 criteria) capable of understanding and willing to take the questionnaires. Protocol: All patients with SLE undergoing follow-up in the rheumatology clinic are recorded in a database. A telephone call was made to all the patients included in the database and those patients who responded to the call and gave their verbal consent for the collection of data from their clinical history and completed the Goldberg questionnaire were finally included. The nurse was in charge of explaining the questionnaire to the patients. Variables: the main outcome variable was depression assessed by Goldberg ( $\geq 2$ depression) and other variables were: previous diagnosis of depression, Charlson index, polypharmacy, psychiatric medication, referral to mental health or primary care, SLEDAI and SLICC. Descriptive, bivariate statistical analysis and multivariate logistic regression analysis (VD: Goldberg depression).

Results: 89 patients with SLE were included (95.5\% women, mean age $49.44 \pm$ 13.2 years and $18.28 \pm 9.19$ years of disease). The mean (SD) of the Goldberg scale in all the patients was $3.2 \pm 2.9$ and a total of 45 patients $(50.4 \%)$ met criteria of depression according to Goldberg's screening, of which 19 (21.3\%) patients had a previous diagnosis of depression. Only 9 patients $(10.1 \%)$ had had a mental health follow-up and 22 patients $(24.7 \%)$ were being followed by the family doctor. A total of 87 patients $(97.8 \%)$ presented polypharmacy: severe polypharmacy $59(66.3 \%)$ and $33(37.1 \%)$ psychiatric medication. The most used psychiatric medication was: 7 (7.8\%) bromazepam, 6 (6.7\%) citalopram, 5 (5.6\%) diazepam. Regarding comorbidities, the Charlson index was $1.82 \pm 1.21$, also highlighting that $34(27 \%)$ of the sample had Sjögren syndrome. In the multivariate analysis, polypharmacy (OR, $1.8[95 \% \mathrm{Cl}, 1.0-3.1])$ and Sjogren's syndrome (OR, 3.8 [95\% Cl, 1.0-10.7]) were independently associated with depression by Goldberg.

Conclusion: Depression is underdiagnosed and undertreated in patients with SLE. Depression is associated with polypharmacy and the perception of patients with SLE of being ill. It is important to correctly treat depression in the context of SLE comorbidity due to its great impact on quality of life.

Disclosure of Interests: None declared

DOI: 10.1136/annrheumdis-2021-eular.3204

\section{HPR Epidemiology and public health (including prevention)}

\section{AB0866-HPR INPATIENT RHEUMATOLOGY HEALTHCARE IN A TERTIARY REFERRAL ACADEMIC HOSPITAL}

C. M. Gamboa-Alonso ${ }^{1}$, G. Figueroa-Parra ${ }^{1}$, A. L. De-Leon-Ibarra ${ }^{1}$, J. DíazAngulo $^{1}$, G. Serna-Peña ${ }^{1}$, D. Vega-Morales ${ }^{1}$, D. Á. Galarza-Delgado ${ }^{1}$.

${ }^{1}$ Universidad Autónoma de Nuevo León, Reumatología e Inmunología Clínica, Monterrey, Mexico

Background: Diagnosis of autoimmune diseases (AD) has been increasing in recent years, with a prevalence of $3-5 \%$ worldwide. The causes that lead to an inpatient approach in patients with suspicion or a confirmed rheumatic disease (RD) vary widely.

$\mathrm{RD}$ are at higher risk of infectious, cardiovascular and other comorbidities due to immunosuppression, a continuous inflammatory state and an altered immune response, increasing morbidity and mortality rates.

Objectives: Describe hospitalized patients who required a rheumatology consultation due to a preexistent or a new RD.

Methods: A descriptive, observational study was performed during a three year follow up (March 2017 -February 2020) in a University Hospital in Mexico. We included patients with definite or suspicion of a RD who received a rheumatologic evaluation. Demographic and clinical characteristics, length of stay and complications such as infection, readmission, use of mechanical ventilation and mortality were registered. Descriptive statistics were used Binary regression models were applied to find association between clinica factors and infection/mortality in RD hospitalized patients, SPSS v20 was used to perform statistical analysis. $A P<0.05$ was considered statistically significant.

Results: A total of 642 hospitalized patients received a rheumatologic evaluation. Of the evaluated patients, $315(49.1 \%)$ had a history of a confirmed RD, of these, $237(75.2 \%)$ were hospitalized due to a complication associated to the underlying RD and 78 were hospitalized for other non-rheumatic nor related disorder and were omitted for the rest of the analysis; $327(50.9 \%)$ patients were evaluated for the first time, $147(45.0 \%)$ of them being diagnosed with a new RD; Systemic Lupus Erythematosus (SLE) 55 (37.4\%) was the most frequent diagnosis. Figure 1

Of the 642 evaluated patients, $384(59.81 \%)$ patients with a previous (237) or new (147) rheumatic cause of hospitalization were studied. Table $1 \mathrm{~A}$

Factors associated to infection and mortality in the 384 patients are shown in Table 1B.

Conclusion: Inpatient rheumatologic evaluation is a major concern of healthcare due to the severity and prognosis of these diseases. SLE was found to be the most common diagnosis in patients evaluated for the first time. Infection is an important cause of hospitalization and mortality, being the use of steroids and immunosuppression some of the main risk factors of these outcomes.

\section{REFERENCES:}

[1] O'Sullivan O, Bateman J, Jobanputra P. 172 Acute Rheumatology Referrals are Increasing: A Service Evaluation of more than 1000 Consecutive Acute Inpatient Referrals from a Tertiary Centre. Rheumatology. 1 de abril de 2016;55(suppl_1):i131-2. 